\title{
Investigating Recent Testing among MSM: Results from Community-Based HIV Rapid Testing Attendees in France
}

\author{
Nicolas Lorente, ${ }^{1,2,3}$ Karen Champenois, ${ }^{4}$ Jérôme Blanche, ${ }^{1,2,3}$ Marie Préau, ${ }^{1,3,5}$ \\ Marie Suzan-Monti, ${ }^{1,2,3}$ Marion Mora, ${ }^{1,2,3}$ Lionel Fugon, ${ }^{6,7}$ Maria Patrizia Carrieri, ${ }^{1,2,3}$ \\ Luis Sagaon-Teyssier, ${ }^{1,2,3}$ Jean-Marie Le Gall, ${ }^{6}$ Bruno Spire, ${ }^{1,2,3,6}$ \\ and Yazdan Yazdanpanah ${ }^{4,8,9}$
}

${ }^{1}$ INSERM, UMR912 (SESSTIM), 13006 Marseille, France

${ }^{2}$ Aix Marseille Université, UMR_S912, IRD, 13006 Marseille, France

${ }^{3}$ ORS PACA, Observatoire Régional de la Santé Provence Alpes Côte d’Azur, 13006 Marseille, France

${ }^{4}$ ATIP/AVENIR, INSERM U738, 75877 Paris, France

${ }^{5}$ GREPS, Université Lyon 2, 69500 Bron, France

${ }^{6}$ AIDES, 93508 Pantin, France

${ }^{7}$ Coalition PLUS, 93508 Pantin, France

${ }^{8}$ Service des Maladies Infectieuses et Tropicales, Hôpital Bichat-Claude Bernard, 75877 Paris, France

${ }^{9}$ Université Denis Diderot, 75877 Paris, France

Correspondence should be addressed to Nicolas Lorente; nicolas.lorente@inserm.fr

Received 8 February 2013; Accepted 24 June 2013

Academic Editor: Mark R. Dybul

Copyright (C) 2013 Nicolas Lorente et al. This is an open access article distributed under the Creative Commons Attribution License, which permits unrestricted use, distribution, and reproduction in any medium, provided the original work is properly cited.

Background. We aimed to identify factors associated with recent HIV testing in MSM who attended two experimental communitybased and nonmedicalized voluntary counselling and testing programmes (CB-VCT) targeting MSM in France. Methods. This analysis was based on data collected in 2009-2011 through a self-administered pretesting questionnaire. An index measuring the level of participants' sexual orientation disclosure was built: the higher the index, the greater the disclosure. Factors associated with recent HIV testing (last test $\leq 1$ year) were identified using a multivariate logistic regression model adjusted for the CB-VCT programme of enrolment. Results. 716 MSM provided data on testing history. Overall, $49 \%$ were recently tested for HIV and 51\% were not. Recently tested MSM had a higher homosexuality disclosure index (adjusted OR [95\% confidence interval]: aOR $=1.2$ [1.1-1.4]), reported more inconsistent condom use during anal sex with men $(\mathrm{aOR}=1.6[1.2-2.1])$, and were less likely to have sex under the influence of club drugs $(\mathrm{aOR}=0.6[0.4-1.0])$. Conclusion. New testing strategies should focus on those who live their homosexuality relatively secretly and those who use club drugs before sex. Governments should develop policies which encourage improved social acceptance of homosexuality as concealment of sexual orientation represents a major barrier to testing.

\section{Introduction}

In resource-rich countries, men who have sex with men (MSM) are greatly affected by the HIV burden [1-7], including France where they account for $40 \%$ of the annual new diagnoses [8]. The French HIV incidence in MSM is 60 times higher than that in the overall population [2]. Although a large proportion of MSM have already been tested for HIV in France $[7,9,10]$, it is estimated that they account for $31 \%$ of the hidden epidemic [11] and for $19 \%$ of the diagnoses made at an advanced disease stage in $2011\left(\mathrm{CD} 4<200 / \mathrm{mm}^{3}\right.$, [8]).

HIV testing has now become a tool to limit the HIV epidemic [12] and is a recognized element of combination prevention based on biomedical (preexposure prophylaxis, treatment as prevention) and behavioural (mainly serosorting and positioning) tools [13-17]. Indeed, knowledge of HIV 
serostatus is the cornerstone of successful combination prevention, as the latter's implementation is adapted according to the individual's serological status.

In France, just as in the USA, guidelines encourage the extension of HIV testing and recommend annual testing of certain population groups at high risk of acquiring HIV, in particular MSM [18-20]. Early detection of HIV leads to adequate linkage to care and treatment initiation, which in turn reduce viral load and limit onward transmission $[13,14$, 21]. Furthermore, it has been demonstrated that half of new HIV contaminations are due to people who are unaware of their HIV infection [22].

Barriers to HIV testing have been highlighted in MSM as well as in the general population. These include the individual's perception of low or no risk of being infected, the fear of testing positive, and concerns about confidentiality and structural barriers, such as the time needed to take the test [23-25]. In addition, inappropriate counselling and moralistic attitudes regarding MSM sexual practices and regarding their testing habits were reported by the gay community as reasons for not testing [26].

The first step taken to overcome such barriers was to bring new HIV testing offers to MSM living in France through two community-based and nonmedicalized voluntary counselling and testing (CB-VCT) programmes: ANRSCOM'TEST [27] and ANRS-DRAG [28]. Testing was included in a comprehensive strategy of HIV exposure risk reduction where sexuality was openly addressed with peers. Among MSM who participated in the ANRS-COM'TEST, roughly $30 \%$ had not been tested for at least two years and reported HIV at-risk behaviours [27]. In order to increase repeat testing, the next step was to understand what leads MSM to go for testing or not. This study aimed to identify factors associated with recent testing in MSM who attended the two CB-VCT programmes (ANRS-COM'TEST and ANRSDRAG) in France.

\section{Methods}

2.1. Intervention and Population. This analysis is based on data from two French CB-VCT programmes using rapid HIV tests exclusively targeting MSM: ANRS-COM'TEST and ANRS-DRAG, reported in detail elsewhere [27, 28].

In brief, both studies were cross-sectional and assessed a nonmedicalized voluntary counselling and testing offer implemented by community members from the French NGO AIDES, a community-based organization that focuses on outreach and prevention services for HIV-exposed populations, including MSM. Although they are not professional healthcare workers, AIDES staff members performed the entire testing procedure using HIV rapid tests and provided specific counselling based on the motivational interview method which they were trained in [29]. The studies were carried out during dedicated weekend or evening sessions once or twice a week. MSM were informed about the availability of the CB-VCT through communication campaigns in gay venues and on the Internet (posters, flyers, web banners, and ads). Eligibility criteria were as follows: being older than 18, being a man, and reporting to have sex with other men.
The ANRS-COM'TEST study was conducted from February 2009 to June 2010 in four French cities: Paris, Lille, Montpellier, and Bordeaux. The study was implemented at various AIDES premises, where potential participants came to be tested following the communication campaign [27]. The ANRS-DRAG study was conducted from March 2010 to April 2011 in free and anonymous VCT centres based in three French cities (Paris, Marseille, and Nice), outside of opening hours. The centres were only open during these hours to MSM who came to be tested using the CB-VCT offer and not to their usual attendees [28].

Both studies were approved by the French comité de protection des personnes (ANRS-COM'TEST: Nord-Ouest III, ANRS-DRAG: Sud-Est III) and the Agence française de sécurité sanitaire des produits de santé (AFSSAPS). All participants had to provide written informed consent before enrolment, and the studies were anonymous.

2.2. Data Collection. All participants had to fill in selfadministered questionnaires during the testing procedure. The present analysis was based on data from the pre-testing questionnaire that collected sociodemographic characteristics, risk perceptions, HIV testing history, and sexual behaviour in the previous six months. Similar questionnaires were used in both studies, allowing us to merge databases.

2.3. Main Outcome and Explanatory Variables. Participants were asked when their last HIV test had been. This variable was then dichotomised into "recently tested" (i.e., the most recent HIV test performed in the 12 months prior to the CBVCT) versus "not recently tested" (i.e., the most recent HIV test performed more than 12 months prior to the CB-VCT or having never been tested). This 12-month cutoff was chosen in accordance with French testing guidelines which recommend a test every year for MSM [18].

Several potential explanatory variables were computed using one or more questions. We built an index of sexual orientation disclosure, measuring the level of disclosure of one's sexual orientation with the question: "Is your homo-, bisexuality known to your ..." and broken down for each of the following categories: father, mother, brother(s) or sister(s), colleagues, and heterosexual friends. The higher the index, the greater the participant's disclosure of his sexual orientation.

Participants were asked to answer several questions about anal sex and condom use with their casual and/or steady partners. We then computed a risk proxy variable of inconsistent condom use (ICU): participants who reported that they had not systematically used condoms during anal intercourse in the previous six months, irrespective of the type of partner, were classified as having ICU.

The questionnaire also collected information about sex under the influence of psychoactive products. The following potential explanatory variables were therefore considered: alcohol, poppers, cannabis, and club drugs grouped together (ecstasy, MDMA, cocaine, and crack).

2.4. Statistical Analysis. A logistic regression model was built to determine factors associated with the outcome, that is, with 
the fact of having been tested in the last 12 months. This model was adjusted for the specific study in which participants were enrolled (ANRS-COM'TEST or ANRS-DRAG) in order to take into account the possible recruitment biases in both studies. Potential explanatory variables of recent testing were individually screened in univariate analyses. Variables achieving a significance level of $\leq 0.25$ were considered eligible for inclusion in the multivariate model. A backward method based on the log-likelihood ratio test (entry threshold $P$-value $\leq 0.05$ ) was then used to select factors independently associated with the outcome. A sensitivity analysis was performed: two additional multivariate models were built using different cut-off points for the outcome variable (11 and 13 months versus 12 in the base-case analysis).

Statistical analyses were performed using SPSS-17 software (SPSS, Inc., Chicago, Illinois, USA) and STATA 12 (StataCorp. 2011. Stata Statistical Software: Release 12. College Station, TX: StataCorp LP).

\section{Results}

3.1. Study Population. Overall, 743 MSM participated in the ANRS-COM'TEST and the ANRS-DRAG studies. Complete data on the most recent HIV test were available for 716 MSM (our study group). The other 27 were excluded from this analysis: 5 men gave no information about history of HIV testing and 22 reported having been previously tested but did not specify the date of the most recent test.

Among the 716 MSM included in this analysis, 517 (71\%) and 199 (28\%) were enrolled in the ANRS-COM'TEST and ANRS-DRAG studies, respectively. Median age was 31 (interquartile range, IQR = [25-39]); 81\% defined themselves as homosexual. Regarding the main outcome, 349 MSM (49\%) were recently tested, that is, reported at least one test in the 12 months previous to the study. Among the 367 MSM (51\%) not recently tested, 146 (40\%) had been tested more than one year but less than two years previously. For the 221 (60\%) not tested within the previous two years, the median time since their last test was 46 months $(\mathrm{IQR}=[33-64])$.

3.2. Comparison of MSM Regarding the Outcome. MSM characteristics according to recent and not recent HIV testing are shown in Table 1. Compared with their not recently tested counterparts, univariate analyses showed that MSM recently tested were younger (median age: 30 versus 32 years, $P=$ $0.03)$, defined themselves more often as homosexual $(86 \%$ versus $77 \%, P=0.06)$, and were more often victims of verbal abuse because of their sexual orientation (24\% versus $16 \%$, $P=0.005)$.

Interestingly, the MSM recently tested had disclosed their homosexuality more than those not tested recently with, respectively, a median sexual orientation disclosure index of 5/5 (i.e., disclosed to all categories outlined above) and 4/5 (i.e., had not disclosed to at least one of those categories, $P<0.001$ ). Among those not recently tested, $68 \%$ had not disclosed their homosexuality to their father.

Recently tested MSM were also more likely to report having had casual male partners ( $87 \%$ versus $82 \%, P=0.06$ ) or steady male partners ( $82 \%$ versus $73 \%, P=0.002)$ in the previous 6 months and to report ICU with male partners (62\% versus $50 \%, P=0.001$ ) than their not recently tested counterparts. However, the total number of sexual male partners in the previous six months was not different between both MSM groups (overall median [IQR] = 11 [4-24]). Those recently tested tended to report less sex with women $(10 \%$ versus $14 \%, P=0.13$ ) than those not recently tested.

Both groups often reported sex under the influence of alcohol (62\%). Those recently tested were more likely to report sex using poppers ( $46 \%$ versus $38 \%, P=0.04$ ) and, to a lesser extent, when they smoked cannabis (27\% versus $22 \%$, $P=0.18)$. However, they tended to report less sex under the influence of club drugs ( $9 \%$ versus $12 \%, P=0.22$ ) compared with not recently tested MSM.

3.3. Factors Associated with Recent HIV Testing. After adjustment for the specific study, factors independently associated with recent HIV testing were as follows: the index of sexual orientation disclosure to relatives and friends (adjusted odds ratio, $\mathrm{aOR}=1.2 ; 95 \%$ confidence interval, $\mathrm{CI}=[1.1-1.4]$ ), ICU $(\mathrm{aOR}=1.6 ; 95 \% \mathrm{CI}=[1.2-2.1])$, and sex under the influence of club drugs $(\mathrm{aOR}=0.6,95 \% \mathrm{CI}=[0.4-1.0])$ (Table 2$)$.

In the sensitivity analysis (Table 3 ), the model remained nearly unchanged when the 11 and 13 months cut-off points were used to define recent testing.

\section{Discussion}

This is the first study investigating recent HIV testing among MSM living in France. Our analysis showed that approximately half of the study group (49\%) had been tested for HIV in the 12 months previous to their participation in the CBVCT programmes. These men were more likely to be out to all their relatives and friends and to report inconsistent condom use (ICU), but they were less likely to have had sex under the influence of club drugs when compared with those not tested for over one year or who had never been tested.

The two CB-VCT programmes reported here reached a significant proportion of MSM who had been recently tested for HIV as well as those who had not. However, our analysis was restricted to a convenience sample of the specific population of MSM who felt the need to be tested for HIV, so we did not provide information about men who were unwilling to be tested. It is important to underline that this study was based on MSM who decided to participate in an alternative HIV testing offer and who may have been reluctant to be tested using conventional HIV testing offers, or who experienced more discrimination based on the sexual orientation.

The French context regarding HIV testing has changed: the government recently decided to authorize the use of HIV rapid tests by nonmedical staff [30]. Currently, many HIV tests are performed by community members. It would be interesting to reconduct such study in a few months in order to verify whether the level of recent testing increased or not and whether the factors influencing the fact of being recently tested remain unchanged.

The sensitivity analysis showed that using different cutoff points for the outcome variable (i.e., tested within the past 11,12 , and 13 months) did not drastically change the basecase model. Thus, the final multivariate model is stable and 
TABLE 1: Comparison of participants regarding the outcome: recently versus not recently tested (univariate analyses, $n=716$ ).

\begin{tabular}{|c|c|c|c|c|c|}
\hline Variables & Items & $\begin{array}{c}\text { Whole } \\
\text { sample } \\
(n=716) \\
n(\%)\end{array}$ & $\begin{array}{c}\text { Recently } \\
\text { tested } \\
(n=349) \\
n(\%)\end{array}$ & $\begin{array}{c}\text { Not recently } \\
\text { tested } \\
(n=367) \\
n(\%)\end{array}$ & $P^{*}$ \\
\hline \multirow{2}{*}{ Study enrolment } & ANRS-DRAG & $199(27.8)$ & $103(29.5)$ & $96(26.2)$ & \\
\hline & ANRS-COM'TEST & $517(70.5)$ & $246(70.5)$ & $271(73.8)$ & 0.32 \\
\hline \multicolumn{6}{|l|}{ Demographics } \\
\hline Age $^{\S}$ & Median $[\mathrm{IQR}]$ & $31[25-39]$ & $30[25-38]$ & $32[25-40]$ & 0.03 \\
\hline \multirow{3}{*}{ Education } & $<$ Secondary school certificate & $93(13)$ & $44(12.6)$ & $49(13.4)$ & \\
\hline & $\leq 2$ years after secondary school & $238(33.2)$ & $119(34.1)$ & $119(32.4)$ & 0.66 \\
\hline & $>2$ years after secondary school & $374(52.2)$ & $179(51.3)$ & $195(53.1)$ & 0.92 \\
\hline \multirow{2}{*}{ Being in active employment } & No & $142(19.8)$ & $72(20.6)$ & $70(19.1)$ & \\
\hline & Yes & $563(78.6)$ & $272(77.9)$ & $291(79.3)$ & 0.61 \\
\hline \multirow{2}{*}{ Being single } & No & $208(29.1)$ & $94(26.9)$ & $114(31.1)$ & \\
\hline & Yes & $506(70.7)$ & $255(73.1)$ & $251(68.4)$ & 0.21 \\
\hline \multicolumn{6}{|c|}{$\begin{array}{l}\text { Sexual orientation, disclosure, and victim of verbal } \\
\text { abuse or aggression }\end{array}$} \\
\hline \multirow{4}{*}{ Sexual orientation } & Homosexual & $582(81.3)$ & $299(85.7)$ & $283(77.1)$ & \\
\hline & Bisexual & $94(13.1)$ & $38(10.9)$ & $56(15.3)$ & 0.05 \\
\hline & Heterosexual & $9(1.3)$ & $0(0)$ & $9(2.5)$ & na \\
\hline & Other & $27(3.8)$ & $10(2.9)$ & $17(4.6)$ & 0.15 \\
\hline Index of sexual orientation disclosure ${ }^{\S}$ & Median [IQR] & $4[2-5]$ & $5[3-5]$ & $4[1-5]$ & $<0.001$ \\
\hline \multirow{2}{*}{$\begin{array}{l}\text { Victim of verbal abuse because of sexual } \\
\text { orientation }\end{array}$} & No & $570(79.6)$ & $263(75.4)$ & $307(83.7)$ & \\
\hline & Yes & $143(20.0)$ & $85(24.4)$ & $58(15.8)$ & 0.005 \\
\hline \multirow{2}{*}{$\begin{array}{l}\text { Victim of aggression because of sexual } \\
\text { orientation }\end{array}$} & No & $682(95.3)$ & $331(94.8)$ & $351(95.6)$ & \\
\hline & Yes & $22(3.1)$ & $11(3.2)$ & $11(3.0)$ & 0.89 \\
\hline \multicolumn{6}{|l|}{ Sexual life (previous 6 months) } \\
\hline Total no. of sex male partners ${ }^{\S}$ & Median [IQR] & $11[4-24]$ & $11[5-30]$ & $10[3-22]$ & 0.48 \\
\hline \multirow{2}{*}{ Having casual male partners } & No & $111(15.5)$ & $45(12.9)$ & $66(18.0)$ & \\
\hline & Yes & $605(84.5)$ & $304(87.1)$ & $301(82.0)$ & 0.06 \\
\hline No. of casual male partners ${ }^{\S}$ & Median [IQR] & $8[3-20]$ & $10[3-22]$ & $7[2-20]$ & 0.53 \\
\hline \multirow{2}{*}{ Having steady male partners } & No & $163(22.7)$ & $62(17.8)$ & $101(27.5)$ & \\
\hline & Yes & $553(77.2)$ & $287(82.2)$ & $266(72.5)$ & 0.002 \\
\hline No. of steady male partner $(s)^{\S}$ & Median [IQR] & $2[1-4]$ & $2[1-4]$ & $2[0-4]$ & 0.58 \\
\hline \multirow{2}{*}{ ICU } & No & $293(40.9)$ & $121(34.7)$ & $172(46.9)$ & \\
\hline & Yes & $401(56.0)$ & $216(61.9)$ & $185(50.4)$ & 0.001 \\
\hline \multirow{2}{*}{ Sex with women } & No & $592(82.7)$ & $297(85.1)$ & $295(80.4)$ & \\
\hline & Yes & $87(12.2)$ & $36(10.3)$ & $51(13.9)$ & 0.13 \\
\hline \multicolumn{6}{|c|}{ Sex under the influence of drugs (previous 6 months) } \\
\hline \multirow{2}{*}{ Alcohol } & No & $275(38.4)$ & $127(36.4)$ & $148(40.3)$ & \\
\hline & Yes & $441(61.6)$ & $222(63.6)$ & $219(59.7)$ & 0.28 \\
\hline \multirow{2}{*}{ Poppers } & No & $418(58.4)$ & $190(54.4)$ & $228(62.1)$ & \\
\hline & Yes & $298(41.6)$ & 159 (45.6) & $139(37.9)$ & 0.04 \\
\hline \multirow{2}{*}{ Cannabis } & No & $541(75.6)$ & $256(73.4)$ & $285(77.7)$ & \\
\hline & Yes & $175(24.4)$ & $93(26.6)$ & $82(22.3)$ & 0.18 \\
\hline \multirow{2}{*}{ Club drugs** } & No & $640(89.4)$ & $317(90.8)$ & $323(88.0)$ & \\
\hline & Yes & $76(10.6)$ & $32(9.2)$ & $44(12.0)$ & 0.22 \\
\hline
\end{tabular}

${ }^{*}$ This column displays $P$ values for each variable tested in univariate logistic regression, showing whether differences between recently tested and not recently tested MSM are significant or not; ${ }^{* *}$ Ecstasy, MDMA, cocaine, or crack.

${ }^{\S}$ Medians were used because these variables did not follow a normal distribution.

IQR: interquartile range; ICU: inconsistent condom use with casual and/or steady male partners; na: not applicable. 
TABLE 2: Factors independently associated with recent testing, adjusted for the study (multivariate analysis, $n=685^{*}$ ).

\begin{tabular}{|c|c|c|c|c|c|c|c|}
\hline Variables & Items & $\begin{array}{c}\text { Recently } \\
\text { tested } \\
\%(n=336)\end{array}$ & $\begin{array}{l}\text { Not recently } \\
\text { tested } \\
\%(n=349)\end{array}$ & OR [95\% CI] & $P$ & aOR [95\% CI] & $P$ \\
\hline Index of sexual orientation disclosure & Median [IQR] & $5[3-5]$ & $4[1-5]$ & $1.2[1.1-1.4]$ & $<0.001$ & $1.2[1.1-1.4]$ & $<0.001$ \\
\hline \multirow{2}{*}{ ICU } & No & 36 & 48 & 1 & & 1 & \\
\hline & Yes & 64 & 52 & $1.7[1.2-2.3]$ & 0.001 & $1.6[1.2-2.1]$ & 0.005 \\
\hline \multirow{2}{*}{ Club drugs ${ }^{* *}$} & No & 91 & 87 & 1 & & 1 & \\
\hline & Yes & 10 & 13 & $0.7[0.5-1.2]$ & 0.22 & $0.6[0.4-1.0]$ & 0.05 \\
\hline \multirow{2}{*}{ Study enrolment } & ANRS-COM'TEST & 70 & 74 & 1 & & 1 & \\
\hline & ANRS DRAG & 30 & 26 & $1.2[0.9-1.6]$ & 0.32 & $1.1[0.8-1.6]$ & 0.43 \\
\hline
\end{tabular}

*Valid dataset for all variables of the model; ${ }^{* *}$ Ecstasy, MDMA, cocaine, or crack.

${ }^{\S}$ Median was used because this variable did not follow a normal distribution.

OR: odds ratio; aOR: adjusted odds ratio; CI: confidence interval; IQR: interquartile range; ICU: inconsistent condom use with casual and/or steady male partners. Log-likelihood $=-456.01$.

TABLE 3: Sensitivity analysis: factors independently associated with recent testing, adjusted for the study and using different cut-off points for the outcome (multivariate analysis, $n=685^{*}$ ).

\begin{tabular}{|c|c|c|c|c|c|c|c|}
\hline \multicolumn{2}{|c|}{ (Recently tested/not recently tested) } & \multicolumn{2}{|c|}{$\begin{array}{c}\text { 12-month cutoff } \\
\text { (base-case analysis) } \\
(49 \% / 51 \%)\end{array}$} & \multicolumn{2}{|c|}{$\begin{array}{l}\text { 11-month cutoff } \\
(46 \% / 54 \%)\end{array}$} & \multicolumn{2}{|c|}{$\begin{array}{l}\text { 13-month cutoff } \\
(51 \% / 49 \%)\end{array}$} \\
\hline Variables & Items & aOR [95\% CI] & $P$ & $\mathrm{aOR}[95 \% \mathrm{CI}]$ & $P$ & $\mathrm{aOR}[95 \% \mathrm{CI}]$ & $P$ \\
\hline $\begin{array}{l}\text { Index of sexual orientation } \\
\text { disclosure }^{\S}\end{array}$ & Median [IQR] & $1.2[1.1-1.4]$ & $<0.001$ & $1.2[1.1-1.3]$ & $<0.001$ & $1.2[1.1-1.3]$ & $<0.001$ \\
\hline \multirow{2}{*}{ ICU } & No & 1 & & 1 & & 1 & \\
\hline & Yes & $1.6[1.2-2.1]$ & 0.005 & $1.7[1.2-2.3]$ & 0.001 & $1.5[1.1-2.1]$ & 0.008 \\
\hline \multirow{2}{*}{ Club drugs ${ }^{* *}$} & No & 1 & & 1 & & 1 & \\
\hline & Yes & $0.6[0.4-1.0]$ & 0.05 & $0.6[0.4-1.0]$ & 0.05 & $0.6[0.4-1.0]$ & 0.05 \\
\hline \multirow{2}{*}{ Study enrolment } & ANRS-COM'TEST & 1 & & 1 & & 1 & \\
\hline & ANRS DRAG & $1.1[0.8-1.6]$ & 0.43 & $1.3[0.9-1.9]$ & 0.12 & $1.17[0.8-1.7]$ & 0.35 \\
\hline
\end{tabular}

*Valid dataset for all variables of the model; ${ }^{* *}$ Ecstasy, MDMA, cocaine, or crack.

${ }^{\S}$ Median was used because this variable did not follow a normal distribution.

aOR: adjusted odds ratio; CI: confidence interval; IQR: interquartile range; ICU: inconsistent condom use with casual and/or steady male partners.

robust; the associations between the explanatory variables and the outcome are not exclusively due to the large size of our sample.

Our results should be interpreted carefully as we cannot exclude recruitment bias arising from differences between the CB-VCT programmes in terms of study period and setting (AIDES' premises versus free and anonymous testing centres). However, the model was adjusted for the specific study in which men were enrolled, and no significant differences were found between both. In addition, the two programmes were carried out in large urban areas. Consequently, results cannot be extrapolated to MSM living in small towns or in the countryside, where living one's homosexuality openly is more complicated due to the fear of being recognized, the fear of outing and being labelled as gay and/or HIV positive.

The present study shows that half of the MSM involved had not been tested for HIV for more than one year. The current situation is far from adhering to French guidelines which recommend annual HIV testing for MSM [18]. Our rate of recent testing is comparable with those in many other studies among MSM conducted in resource-rich countries, from $43 \%$ in the UK to $54 \%$ in the USA [31-35]. However, one French study conducted among MSM attending gay venues in Paris (the Prevagay study) showed that $63 \%$ of participants had been tested within the previous 12 months [7]. These men reported attending various gay venues quite frequently, where HIV prevention is very present. It has been shown elsewhere that recent testing is associated with exposure to HIV prevention [36]; this may explain the higher rate of recently tested MSM in PREVAGAY compared with our study. Furthermore, attending such venues-identified as gay venues-requires the individual to be at least a little comfortable with his homosexuality in order to overcome the fear of outing.

In our study, recently tested MSM had a higher index of sexual orientation disclosure $(5 / 5)$ that is, they lived their homosexuality openly with all their relatives and friends, compared with nonrecently tested MSM (4/5). This finding has also been highlighted in a large US study among young MSM [33] and more recently in the European MSM Internet 
Survey (the EMIS study) [10, 37], where being out sexually to many people was positively associated with recent testing. In a recent French Internet survey on MSM, men who accessedor who were interested in accessing - self-tests were also more likely to not have been tested recently and to live their sexual lives with men in absolute secrecy [38,39].

Our results confirm that nondisclosure of sexual orientation is a major barrier to testing, and therefore to repeat testing among MSM. Nonrecently tested MSM were significantly less likely to be out; they were also more likely to define themselves as nonhomosexual and to report that they had sex with women compared with their recently tested counterparts. Interestingly, in a US study conducted among MSM, the desire to be perceived by others as heterosexual was negatively associated with recent testing, their belief being that "HIV testing is so gay" [35]. In Lebanon, a recent study highlighted that MSM who had disclosed their homosexuality to family and parents were more likely to have been tested for HIV [40]. In France, homosexuality is no longer criminalized and seems to be better accepted than in Lebanon for example, but many MSM do not live their homosexuality openly, probably because of quite widespread discrimination on the grounds of sexual orientation [41].

Unlike other studies which showed that a higher number of sex partners were associated with higher odds of recent testing $[32,35]$, we found no difference between recently and not recently tested MSM regarding the number of sex partners (high in both groups). On the other hand, those reporting ICU were significantly more likely to be recently tested. Not perceiving oneself to be at risk of acquiring HIV is a wellknown barrier to HIV testing and is common in MSM as well as in the general population $[23,25,42]$. It is thus important to increase the self-perception of being at risk among those not recently tested and reporting ICU.

The use of psychoactive products is associated with sexual risk behaviours and with a higher prevalence of HIV and other sexually transmitted diseases in MSM [43-46]. In our study, not recently tested MSM were significantly more likely to report sex under the influence of club drugs than their recently tested counterparts. The homosexuality disclosure variable seemed to play the role of what is known as a "suppressor variable" [47]: introducing the latter increased the explanatory significance of club drug use and consequently the quality of the model (i.e., log-likelihood (LL) was significantly higher when the homosexuality disclosure variable was introduced; $\mathrm{LL}_{\text {with revelation variable }}=-456.01$ versus $\left.\mathrm{LL}_{\text {without revelation variable }}=-474.05\right)$. This is not such a striking result in social science research, and particularly in behavioural studies [48]. The phenomenon suggests that club drugs use and homosexuality disclosure share important information and should be interpreted as a composite. Further qualitative research is needed to better identify behaviours, beliefs, and attitudes which mediate the relationship between club drug use, disclosure of homosexuality, and HIV testing.

Although repeating HIV testing is being promoted in MSM who engage in at-risk sexual behaviour, prevention efforts to reach MSM who are tested less frequently should be focused on those who use club drugs, particularly before sex, and those who live their homosexuality in relative secrecy. Increasing self-perception of risk among MSM should be an intervention included in a comprehensive and understandable prevention message for all MSM. In addition, governments should develop policies which encourage improved social acceptance of homosexuality, as concealment of sexual orientation represents a major barrier to testing and might impede health and well-being of sexual minorities.

\section{Authors' Contribution}

NL, KC, BS and YY conceived and designed the study. KC, JMLG and YY implemented the ANRS-COM'TEST study. NL, MM, MP, MSM and BS implemented the ANRS-DRAG study. JB, LF and LST performed the statistical analysis. All authors contributed to the results' interpretation. KC and NL wrote the manuscript. All authors critically revised the manuscript, and approved the final version. NL and KC contributed equally to this work.

\section{Acknowledgments}

The authors gratefully acknowledge all the AIDES counsellors for their involvement in ANRS-COM'TEST and ANRSDRAG and all those who agreed to participate in these studies. The authors would also like to thank the French Agency for AIDS Research (ANRS) for financial support and Jude Sweeney for the English revision. N. Lorente and K. Champenois are the first coauthors.

\section{References}

[1] J. Prejean, R. Song, A. Hernandez et al., "Estimated HIV incidence in the United States, 2006-2009," PLoS ONE, vol. 6, no. 8, Article ID e17502, 2011.

[2] S. Le Vu, Y. Le Strat, F. Barin et al., "Population-based HIV-1 incidence in France, 2003-08: a modelling analysis," The Lancet Infectious Diseases, vol. 10, no. 10, pp. 682-687, 2010.

[3] S. Le Vu, A. Velter, L. Meyer et al., "Biomarker-based HIV incidence in a community sample of men who have sex with men in Paris, France," PLoS ONE, vol. 7, Article ID e39872, 2012.

[4] G. Likatavicius and M. J. van de Laar, "HIV and AIDS in the European Union, 2008," Euro Surveill, vol. 14, no. 47, 2009.

[5] T. J. Finlayson, B. Le, A. Smith et al., "HIV risk, prevention, and testing behaviors among men who have sex with mennational HIV behavioral surveillance system, 21 U.S. Cities, United States, 2008," Morbidity and Mortality Weekly Report, vol. 60, no. 14, pp. 1-34, 2011.

[6] I. A. V. Jansen, R. B. Geskus, U. Davidovich et al., "Ongoing HIV-1 transmission among men who have sex with men in Amsterdam: a 25-year prospective cohort study," AIDS, vol. 25, no. 4, pp. 493-501, 2011.

[7] A. Velter, F. Barin, A. Bouyssou et al., "HIV prevalence and sexual risk behaviors associated with awareness of HIV status among men who have sex with men in Paris, France," AIDS and Behavior, vol. 17, no. 4, pp. 1266-1278, 2012.

[8] F. Cazein, Y. Le Strat, J. Pillonel et al., "HIV testing and new HIV diagnoses, France, 2003-2010," Bulletin Épidémiologique Hebdomadaire, vol. 44, pp. 43-8, 2011. 
[9] A. Velter, A. Bouyssou-Michel, J. Pillonel, G. Jacquier, and C. Semaille, "Baromètre gay 2005: enquête auprès des hommes fréquentant les lieux de rencontre gay franciliens," Bulletin Épidémiologique Hebdomadaire, vol. 25, pp. 178-180, 2006.

[10] A. Schmidt, U. Marcus, M. Breveglieri et al., "Individual level and country level predictors for recent HIV-testing and late HIV diagnoses among MSM in Europe-aspects to consider when planning interventions to increase HIV-testing. Results of the European MSM Internet Survey (EMIS)," in HIV in Europe, Copenhagen, Denmark, 2012.

[11] V. Supervie, J. D. Ndawinz, and D. Costagliola, "How to estimate the size of the hidden HIV epidemic? The case of France HIV," in Proceedings of the Europe Conference, HIV in Europe, Copenhagen, Danmark, 2012.

[12] R. M. Granich, C. F. Gilks, C. Dye, K. M. De Cock, and B. G. Williams, "Universal voluntary HIV testing with immediate antiretroviral therapy as a strategy for elimination of HIV transmission: a mathematical model," The Lancet, vol. 373, no. 9657, pp. $48-57,2009$.

[13] S. Attia, M. Egger, M. Müller, M. Zwahlen, and N. Low, "Sexual transmission of HIV according to viral load and antiretroviral therapy: systematic review and meta-analysis," AIDS, vol. 23, no. 11, pp. 1397-1404, 2009.

[14] M. S. Cohen, Y. Q. Chen, M. McCauley et al., "Prevention of HIV-1 infection with early antiretroviral therapy," The New England Journal of Medicine, vol. 365, no. 6, pp. 493-505, 2011.

[15] R. M. Grant, J. R. Lama, P. L. Anderson et al., "Preexposure chemoprophylaxis for HIV prevention in men who have sex with men," The New England Journal of Medicine, vol. 363, no. 27, pp. 2587-2599, 2010.

[16] G. J. Hart and J. Elford, "Sexual risk behaviour of men who have sex with men: emerging patterns and new challenges," Current Opinion in Infectious Diseases, vol. 23, no. 1, pp. 39-44, 2010.

[17] L. M. McDaid and G. J. Hart, "Sexual risk behaviour for transmission of HIV in men who have sex with men: recent findings and potential interventions," Current Opinion in HIV and AIDS, vol. 5, no. 4, pp. 311-315, 2010.

[18] H. A. de Santé, Recommandations en santé publiqueDépistage de l'infection par le VIH en France-Stratégies et dispositif de dépistage, 2009.

[19] Y. Yazdanpanah, C. E. Sloan, C. Charlois-Ou et al., "Routine HIV screening in France: clinical impact and cost-effectiveness," PLoS ONE, vol. 5, no. 10, Article ID e13132, 2010.

[20] K. A. Workowski and S. M. Berman, "Sexually transmitted diseases treatment guidelines, 2006," Morbidity and Mortality Weekly Report, vol. 55, no. -11, pp. 1-94, 2006.

[21] T. C. Quinn, M. J. Wawer, N. Sewankambo et al., "Viral load and heterosexual transmission of human immunodeficiency virus type 1," The New England Journal of Medicine, vol. 342, no. 13, pp. 921-929, 2000.

[22] H. Irene Hall, D. R. Holtgrave, and C. Maulsby, "HIV transmission rates from persons living with HIV who are aware and unaware of their infection," AIDS, vol. 26, no. 7, pp. 893-896, 2012.

[23] D. A. MacKellar, S.-I. Hou, C. C. Whalen et al., "Reasons for not HIV testing, testing intentions, and potential use of an over-thecounter rapid HIV test in an internet sample of men who have sex with men who have never tested for HIV," Sexually Transmitted Diseases, vol. 38, no. 5, pp. 419-428, 2011.

[24] S. Schwarcz, T. A. Richards, H. Frank et al., "Identifying barriers to HIV testing: personal and contextual factors associated with late HIV testing," AIDS Care, vol. 23, no. 7, pp. 892-900, 2011.
[25] J. Deblonde, P. De Koker, F. F. Hamers, J. Fontaine, S. Luchters, and M. Temmerman, "Barriers to HIV testing in Europe: a systematic review," European Journal of Public Health, vol. 20, no. 4, pp. 422-432, 2010.

[26] B. Spire, I. de Zoysa, and H. Himmich, "HIV prevention: what have we learned from community experiences in concentrated epidemics?" Journal of the International AIDS Society, vol. 11, article 5, 2008

[27] K. Champenois, J. M. Le Gall, C. Jacquemin et al., "ANRSCOM'TEST: description of a community-based HIV testing intervention in non-medical settings for men who have sex with men," BMJ Open, vol. 2, Article ID e000693, 2012.

[28] N. Lorente, M. Preau, C. Vernay-Vaisse et al., "Expanding access to non-medicalized community-based rapid testing to men who have sex with men: an urgent HIV prevention intervention (The ANRS-DRAG Study)," PLoS ONE, vol. 8, Article ID e61225, 2013.

[29] W. R. Miller and S. Rollnick, "Motivational interviewing," in Preparing People To Change Addictive Behavior, Guilford Press, New York, NY, USA, 2nd edition, 2002.

[30] Arrêté du 9 novembre 2010 fixant les conditions de réalisation des tests rapides d'orientation diagnostique de l'infection à virus de l'immunodéficience humaine (VIH 1 et 2), pp. 20499-20506, 2010.

[31] M. Desai, S. Desai, A. K. Sullivan et al., "Audit of HIV testing frequency and behavioural interventions for men who have sex with men: policy and practice in sexual health clinics in England," Sexually Transmitted Infections, vol. 89, no. 5, pp. 404408, 2013.

[32] M. Holt, P. Rawstorne, J. Wilkinson, H. Worth, M. Bittman, and S. Kippax, "HIV testing, gay community involvement and internet use: social and behavioural correlates of HIV testing among Australian men who have sex with men," AIDS and behavior, vol. 16, no. 1, pp. 13-22, 2012.

[33] D. A. Mackellar, L. A. Valleroy, J. E. Anderson et al., "Recent HIV testing among young men who have sex with men: correlates, contexts, and HIV seroconversion," Sexually Transmitted Diseases, vol. 33, no. 3, pp. 183-192, 2006.

[34] L. M. McDaid and G. J. Hart, "Increased HIV testing and reduced undiagnosed infection among gay men in Scotland, 2005-8: support for the opt-out testing policy?" Sexually Transmitted Infections, vol. 87, no. 3, pp. 221-224, 2011.

[35] M. C. Parent, C. Torrey, and M. S. Michaels, "HIV testing is so gay': the role of masculine gender role conformity in HIV testing among men who have sex with men," Journal of Counseling Psychology, vol. 59, pp. 465-470, 2012.

[36] E. Sumartojo, C. Lyles, K. Choi et al., "Prevalence and correlates of HIV testing in a multi-site sample of young men who have sex with men," AIDS Care, vol. 20, no. 1, pp. 1-14, 2008.

[37] U. Marcus, A. J. Schmidt, R. Berg et al., "Differences in association between HIV testing and risk taking among men having sex with men accross Europe-results of the European MSM Internet Survey (EMIS). Abstract TUPE492," in XIX international AIDS conference, Washington, DC, USA, 2012.

[38] T. Greacen, D. Friboulet, L. Fugon, S. Hefez, N. Lorente, and B. Spire, "Access to and use of unauthorised online HIV selftests by internet-using French-speaking men who have sex with men," Sexually Transmitted Infections, vol. 25, pp. 49-54, 2012.

[39] T. Greacen, D. Friboulet, L. Fugon, S. Hefez, N. Lorente, and B. Spire, "Access to and use of unauthorised online HIV selftests by internet-using French-speaking men who have sex with men," Sexually Transmitted Infections, vol. 88, pp. 368-374, 2012. 
[40] G. J. Wagner, F. M. Aunon, R. L. Kaplan et al., "Qualitative exploration of sexual risk and HIV testing behaviors among men who have sex with men in Beirut, Lebanon," PLoS ONE, vol. 7, Article ID e45566, 2012.

[41] TNS Opinion \& Social, "Eurobarometer 393. Discrimination in the EU in 2012," in European Commission, 2012.

[42] L. Dowson, C. Kober, N. Perry, M. Fisher, and D. Richardson, "Why some MSM present late for HIV testing: a qualitative analysis," AIDS Care, vol. 24, no. 2, pp. 204-209, 2012.

[43] G. Mansergh, S. Flores, B. Koblin, S. Hudson, D. McKirnan, and G. N. Colfax, "Alcohol and drug use in the context of anal sex and other factors associated with sexually transmitted infections: results from a multi-city study of high-risk men who have sex with men in the USA," Sexually Transmitted Infections, vol. 84, no. 6, pp. 509-511, 2008.

[44] D. G. Ostrow, M. W. Plankey, C. Cox et al., "Specific sex drug combinations contribute to the majority of recent HIV seroconversions among MSM in the MACS," Journal of Acquired Immune Deficiency Syndromes, vol. 51, no. 3, pp. 349-355, 2009.

[45] G. Lambert, J. Cox, T. S. Hottes et al., "Correlates of unprotected anal sex at last sexual episode: analysis from a surveillance study of men who have sex with men in Montreal," AIDS and Behavior, vol. 15, no. 3, pp. 584-595, 2011.

[46] K. Champenois, A. Cousien, B. Ndiaye et al., "Risk factors for syphilis infection in men who have sex with men: results of a case-control study in Lille, France," Sexually Transmitted Infections, vol. 89, pp. 128-132, 2013.

[47] D. P. MacKinnon, J. L. Krull, and C. M. Lockwood, "Equivalence of the mediation, confounding and suppression effect," Prevention Science, vol. 1, no. 4, pp. 173-181, 2000.

[48] G. H. Maassen and A. B. Bakker, "Suppressor variables in path models: definitions and interpretations," Sociological Methods and Research, vol. 30, no. 2, pp. 241-270, 2001. 


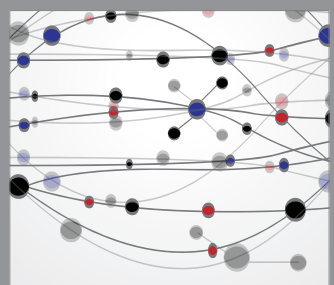

The Scientific World Journal
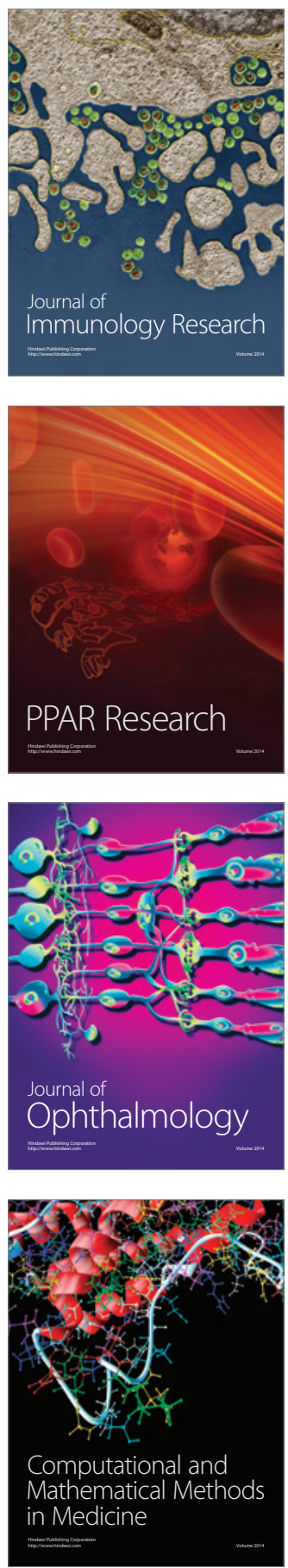

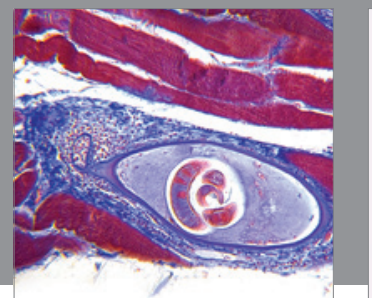

Gastroenterology

Research and Practice
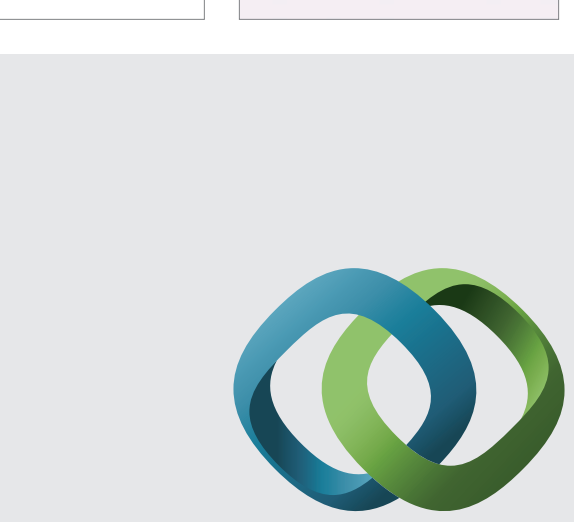

\section{Hindawi}

Submit your manuscripts at

http://www.hindawi.com
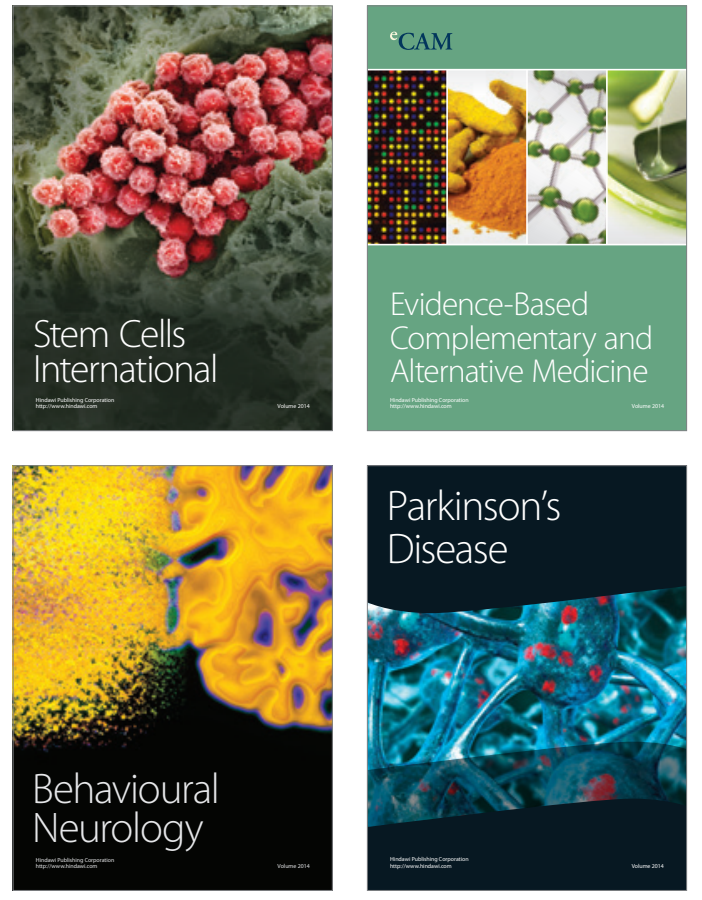
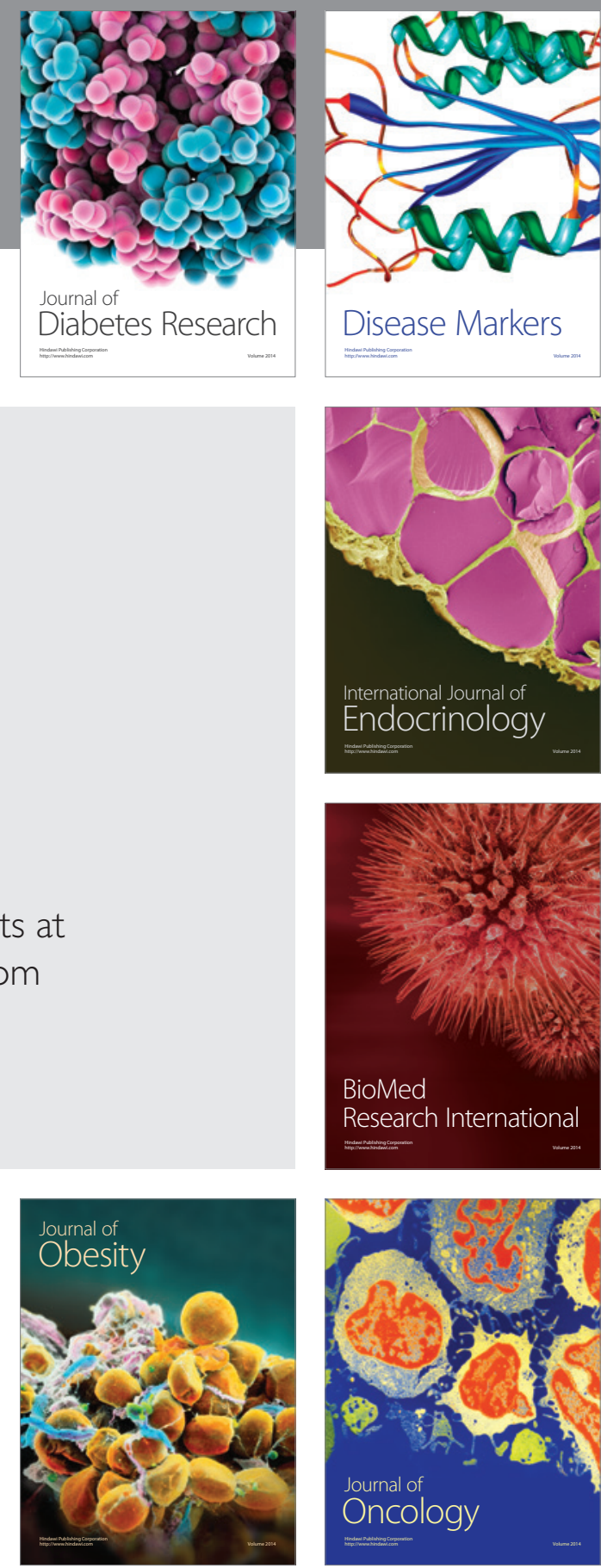

Disease Markers
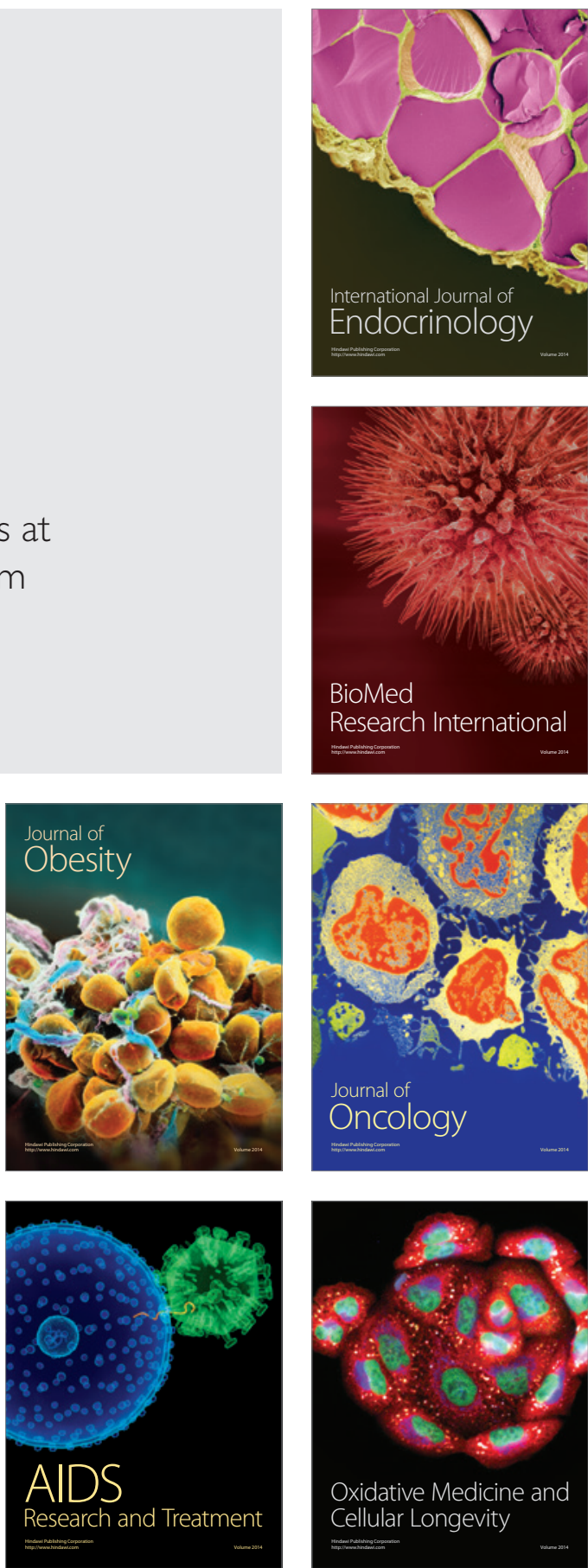